\title{
Imaging Subsurface Characterization at Bukit Bunuh Using 2D Resistivity Method: The Effectiveness of Enhancing Horizontal Resolution (EHR) Technique
}

\author{
Muztaza M. Nordiana, S. Rosli, Saidin M. Mokhtar, Nordin M. M. Nawawi, and Ismail N. Azwin, \\ Member, IACSIT
}

\begin{abstract}
D resistivity method is an indirect method to the shallow subsurface survey for maintaining the geo-environment. It is used to measure the apparent resistivity of subsurface. This study was conducted at Bukit Bunuh, Perak (Malaysia), where EHR resistivity technique was developed in order to get detail and deeper penetration for shallow subsurface study. The survey line for EHR technique was executed in West-East direction while South-North direction was covered without EHR technique. The $2 \mathrm{D}$ resistivity results were compared between the survey line, with and without EHR technique. The survey used Pole-dipole array with $5 \mathrm{~m}$ minimum electrode spacing. The results show the first zone with resistivity value of $10-800 \mathrm{ohm}-\mathrm{m}$ and thickness $5-60 \mathrm{~m}$ as alluvium consisting of boulders (weathered granite) with resistivity value of $>6000$ ohm-m. The second zone with resistivity value $>20000 \mathrm{ohm}-\mathrm{m}$ was granitic bedrock. The penetration depth for $2 D$ resistivity without EHR technique is $70 \mathrm{~m}$ and with EHR techniques is $140 \mathrm{~m}$ with $5 \mathrm{~m}$ electrode spacing.
\end{abstract}

Index Terms-Bukit bunuh, enhancing horizontal resolution (EHR), subsurface, 2D resistivity.

\section{INTRODUCTION}

The shallow subsurface of the earth is an extremely important zone that supports our industrial and infrastructure. As safe and effective use of the near-surface environment is a major challenge facing our society, there is a great need to improve our understanding of the shallow subsurface. These challenging grounds are either hilly terrain or land with underlying materials of notorious mechanical characteristics, such as soft compressible deposits, loose granular deposits, brown fills, karstic limestone, waste dumps and peaty soil. The forms of structure proposed in this modern day demands taller and heavier structures, deeper depth of foundation and underground excavation [1]. Therefore, for projects involving subsurface or substructure works with foundation and underground space excavation; site formation with cut slope, fill, retaining structures and ground improvement works, geotechnical engineer and geophysicist are usually

Manuscript received August 8, 2012; revised September 9, 2012. This work was supported by Centre for Global Archeological Research (CGAR), University Sains Malaysia.

M. M. Nordiana, S. Rosli, M. N. M. Nawawi and I. N. Azwin are with the Geophysics Section, School of Physics, 11800 Universiti Sains Malaysia, Pulau Pinang, Malaysia (email: mmnordiana@gmail.com; rosli@usm.my; mnawawi@usm.my; nurazwinisnail@yahoo.com)

S. Mokhtar is with the Centre for Global Archeological Research Malaysia, 11800 Universiti Sains Malaysia, Pulau Pinang, Malaysia (e-mail: mmokh@usm.my). engaged in ground investigation and geotechnical and geophysical designs.

Geotechnical studies are usually used for subsurface, engineering and environmental works. Geophysical study provides supported data in order to save cost and time. Geophysical methods can be used to determine depth to bedrock, nature of overburden materials and near surface structures such as sinkholes, cavities, voids, faults and boulders [2].

This paper aims to show how 2D resistivity methods were successfully used for detection in shallow subsurface. An important part of this study is to improve the 2D resistivity horizontal resolution and prove a detail image of deep structure can be obtained using EHR technique.

\section{2D RESISTIVITY METHOD}

\section{A. Theory of $2 D$ Resistivity}

The $2 \mathrm{D}$ resistivity measurements are normally made by injecting current into the ground through two current electrodes, $C_{1}$ and $C_{2}$ and measuring the resulting voltage difference at two potential electrodes, $\mathrm{P}_{1}$ and $\mathrm{P}_{2}$ (Fig. 1). The resistivity of a soil or rock is dependent on several factors that include amount of interconnected pore water, porosity, amount of total dissolved solid such as salts and mineral composition (clays). The 2D DC resistivity method is described by [3], [4], [5] and [6].

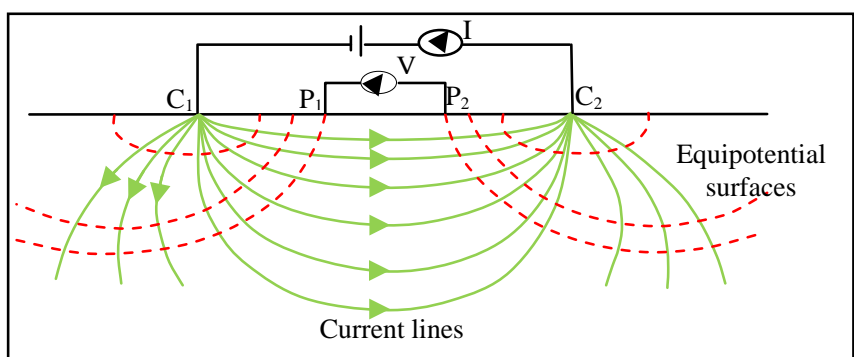

Fig. 1. Four-point electrode configuration in a two-layer model of resistivity, $\rho_{1}$ and $\rho_{2}$. I, current; U, voltage; C, current electrode; P, potential electrode [7].

\section{B. Enhancing Horizontal Resolution (EHR) Technique}

When two current electrodes are placed close to one another, current flows along arc-shaped paths connecting the two electrodes. About $50 \%$ of the current flows through rock at depths shallower than the current electrode spacing provided the earth has a constant resistivity. By increasing 
the electrode spacing, more of the injected current will flow to greater depths, as indicated in Fig. 2a. If the electrode spacing is much closer, current flows mostly near the earth surface and apparent resistivity will be dominated by resistivity structure of the near surface [8].

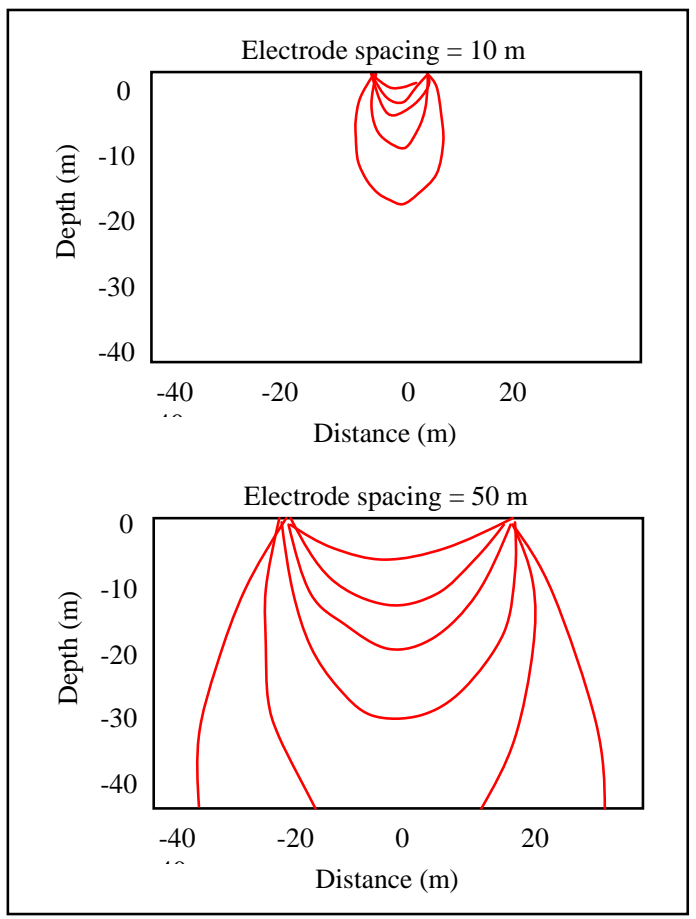

Fig. 2. Current flow through the earth with different electrode spacing.

\section{MATH}

Using EHR technique, the current will flow close to each other at a greater depth (Fig. 3).

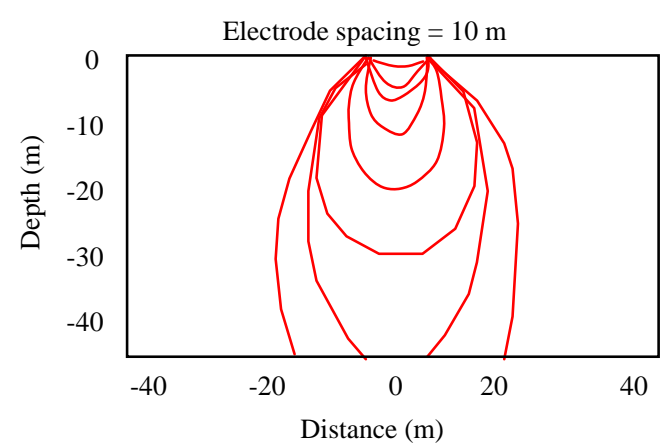

Fig. 3. Current flow through the earth with EHR technique

The important part of this study is to show that EHR technique can improve the $2 \mathrm{D}$ resistivity pseudo section and prove to get deeper penetration. 2D resistivity survey is to determine the subsurface resistivity distribution by taking measurements on the ground surface. The true resistivity of the subsurface can be estimated [9]. Fig. 4 shows the datum points for Pole-dipole arrays with and without EHR technique.

\section{Methodology}

The survey used ABEM SAS4000 system with
Pole-dipole array. The survey lines were directed towards South-North and West-East direction with $5 \mathrm{~m}$ minimum electrode spacing. A total of 41 electrodes were used. The survey line of South-North direction used 2D resistivity method without EHR technique. The survey line of West-East direction was conducted using EHR technique where the first electrode was located at $0 \mathrm{~m}$ (beginning of the line) while the last electrode was located at $400 \mathrm{~m}$ (end of the line). The inter electrode spacing of $10 \mathrm{~m}$ was adopted for the study. After completion of data acquisition, the first electrode was shifted to the right by $5 \mathrm{~m}$ while the last electrode was located at $405 \mathrm{~m}$ and the process of data acquisition was repeated in the same line. The two sets of data acquired for each array was then combined during processing. The acquired data were processed using Res2Dinv software.

a)

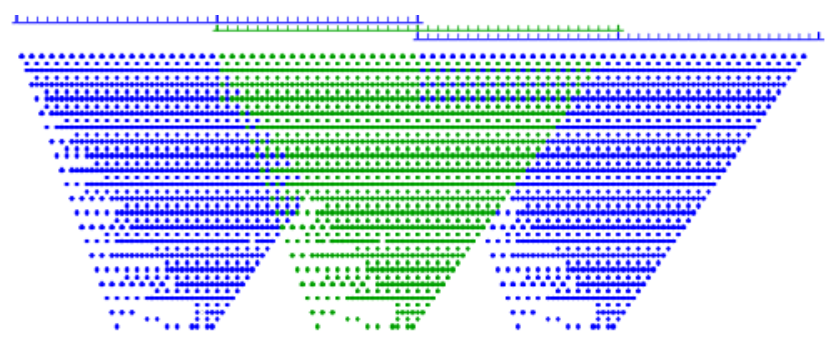

b)

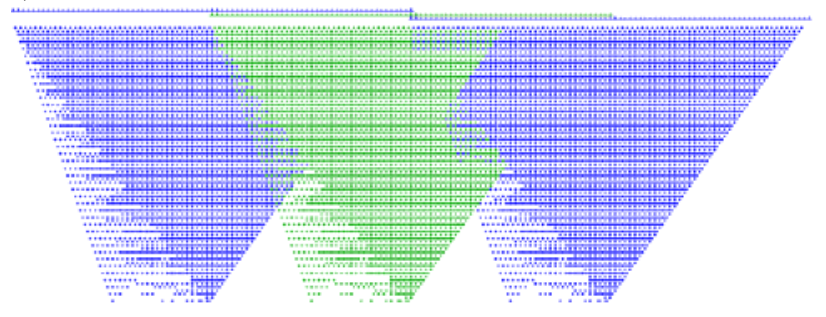

Fig. 4. 2D resistivity datum points to build up a pseudo section, a) common Pole-dipole array b) Pole-dipole array with EHR technique.

\section{STUDY AREA}

The study was carried out in Bukit Bunuh, Perak, Malaysia (Fig. 5). The total length of the study line without EHR technique was $6 \mathrm{~km}$ from South to North, parallel to Sungai Perak. The length of study line using EHR technique $8 \mathrm{~km}$, from West to East direction, perpendicular to Sungai Perak and two mountain ranges, Bintang and Titiwangsa Range.

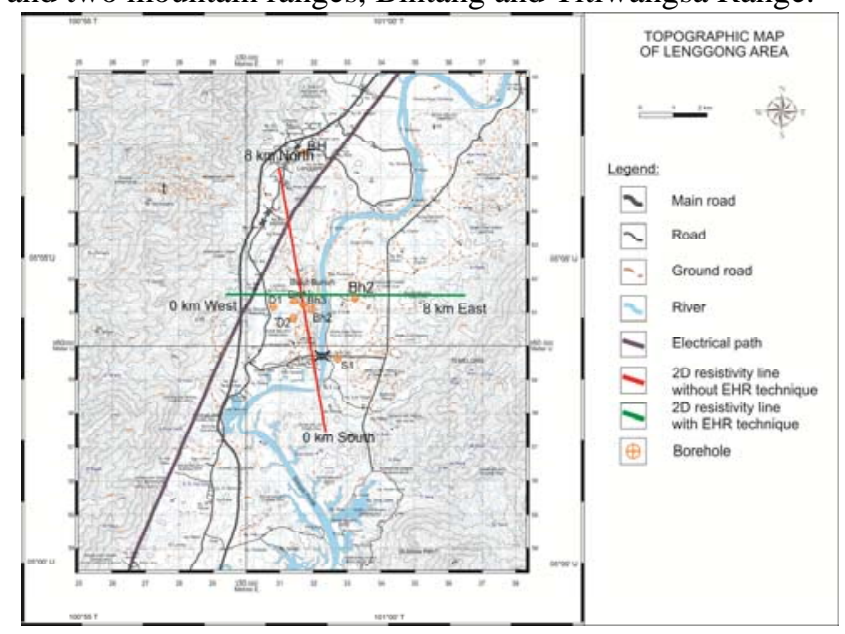

Fig. 5. 2D resistivity survey at Bukit Bunuh, Perak (Malaysia). 


\section{RESUlTS AND DisCUSSIONS}

Resistivity section (Fig. 6-8) show the study area consists of two main zones. The first zone with resistivity value of 10-800 ohm-m and thickness 5-60 m was interpreted as alluvium. There were many boulders (weathered granite) with resistivity value of $>6000$ ohm-m embedded in the alluvium. The second zone with resistivity value $>20000$ ohm-m was granitic bedrock. A lot of fractures (dashed line) were found along the survey line. The results of South-North direction, without EHR technique (Fig. 6) shows the deepest penetration is about $70 \mathrm{~m}$, while East-West direction with EHR technique is $140 \mathrm{~m}$ (Fig. 7 and Fig. 8) with $5 \mathrm{~m}$ minimum electrode spacing.

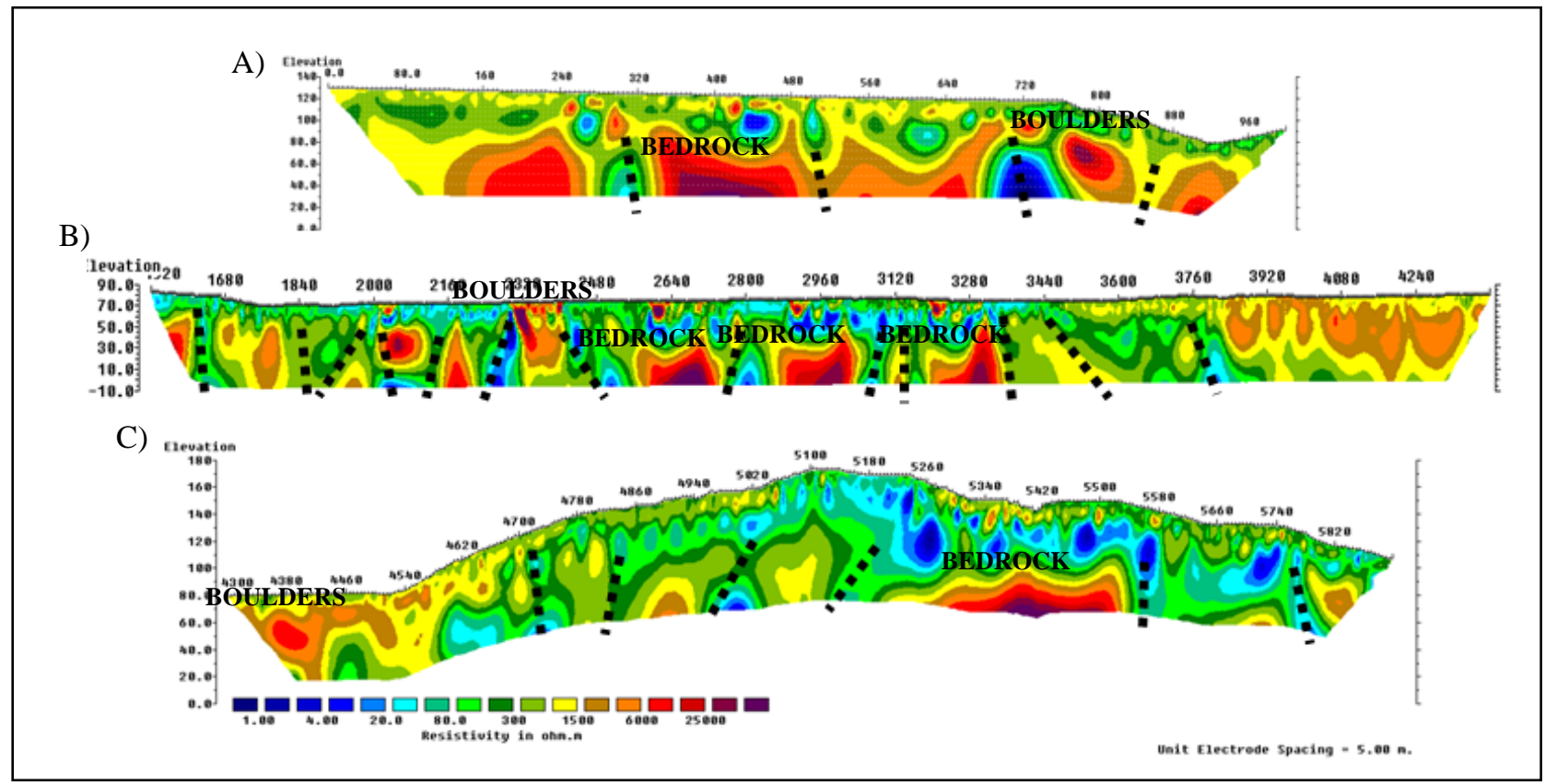

Fig. 6. Resistivity section of South-North line without EHR technique, 6 km length. A) Resistivity section 0-1000 m. B) Resistivity section 1520-4400 m. C) Resistivity section $4300-6000 \mathrm{~m}$.

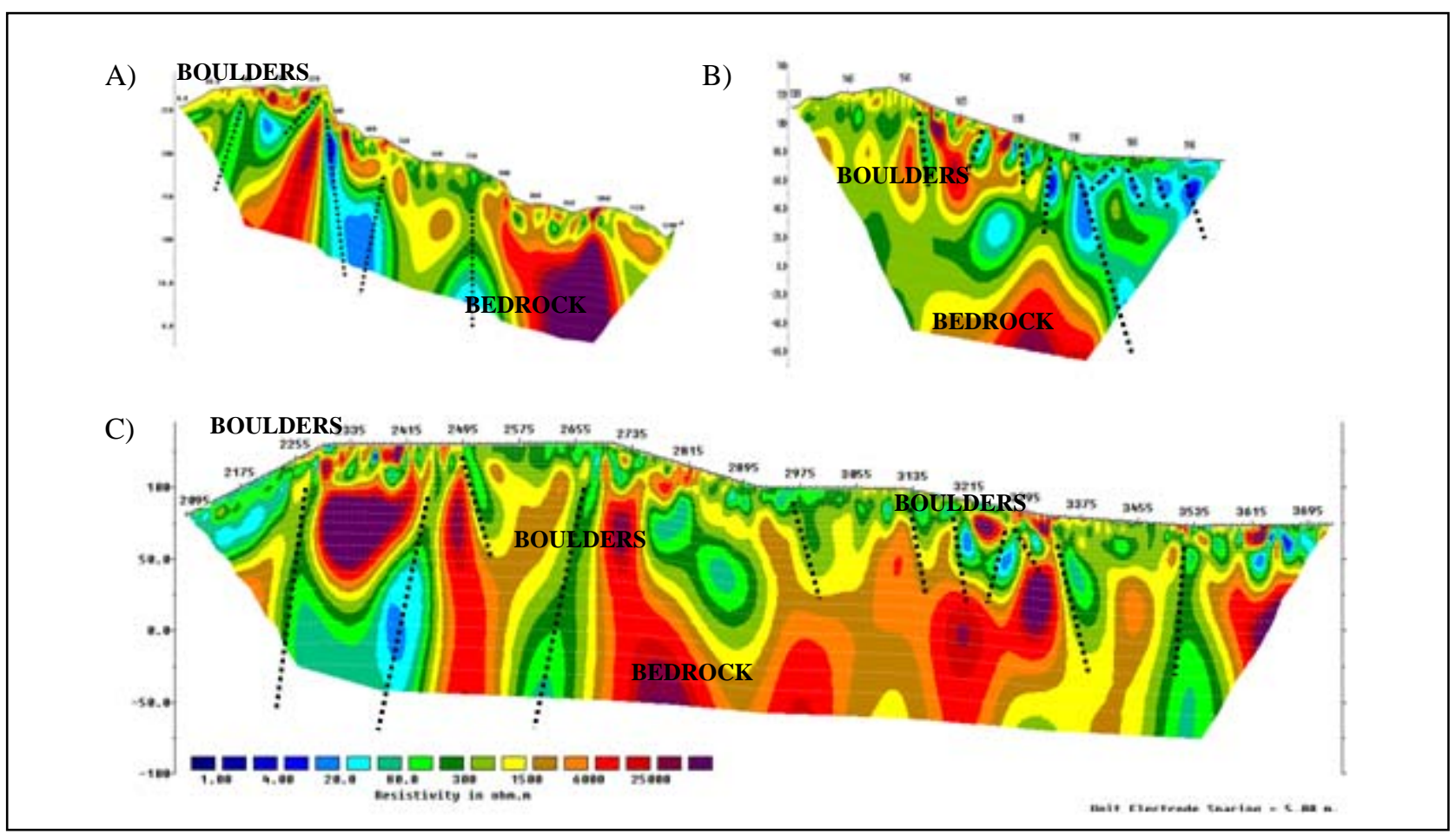

Fig. 7. Resistivity section of West-East line, with EHR technique. A) Resistivity section of 0-1200 m, B) Resistivity section of 1385-1995 m and C) Resistivity section of 2095-3730 m. 


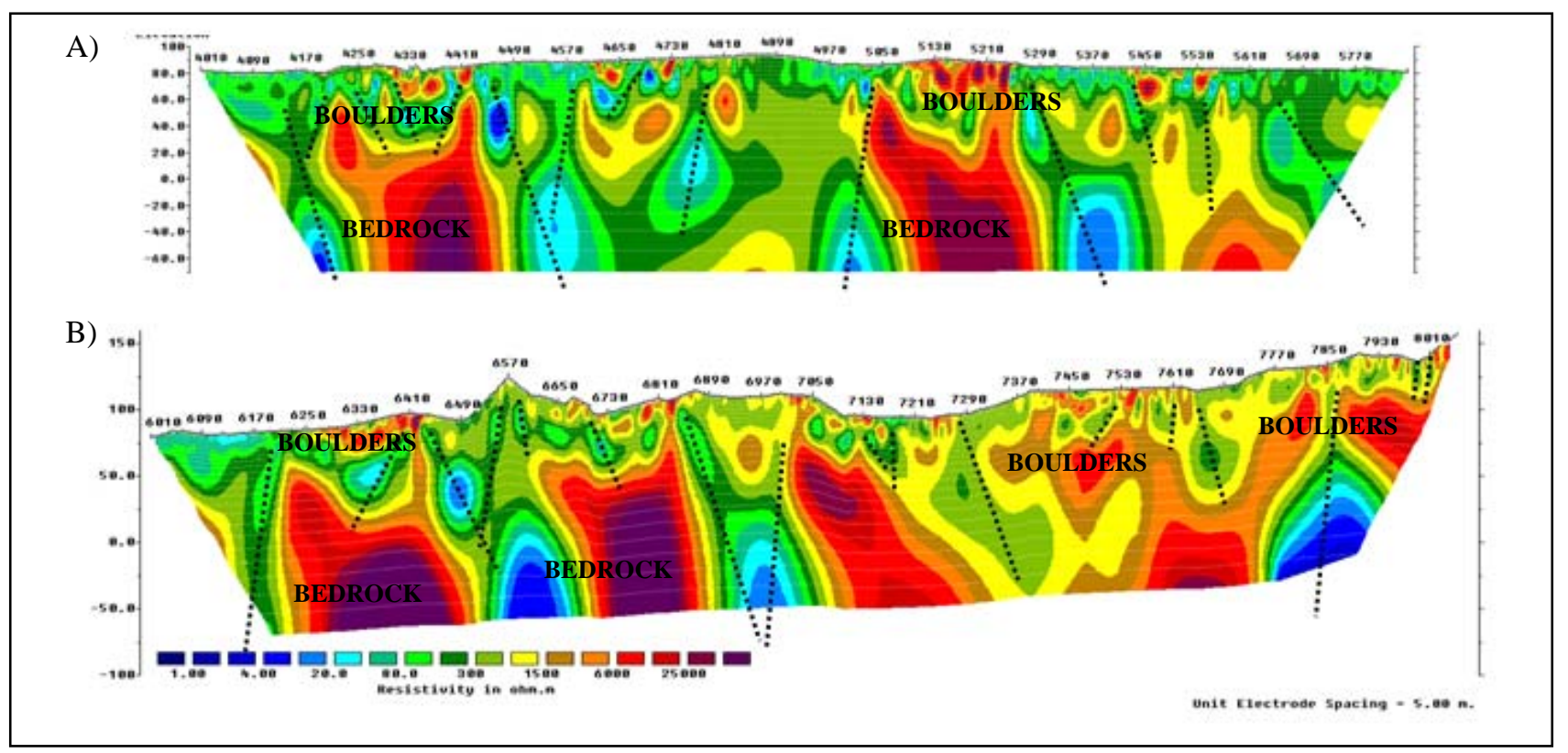

Fig. 8. Resistivity section of West-East line, with EHR technique, A) Resistivity section of 4010-5850 m and B) Resistivity section of 6010-8020 m

\section{CONCLUSION}

The South-North and West-East direction result shows variation in resistivity values and depth of penetration. However, result from the EHR technique produced better image mapping in term of resolutions and penetration depth. This technique improves the horizontal resolution of subsurface resistivity. Application of combining data in resistivity surveys may be a useful strategy for improved resistivity mapping in shallow subsurface.

\section{ACKNOWLEDGMENTS}

Authors wish to express gratitude to USM geophysics staff together with undergraduate and postgraduate students for assistance in geophysics data acquisition.

\section{REFERENCES}

[1] S. S. Liew, Role of Geotechnical Engineer in Civil Engineering works in Malaysia, 2010

[2] S. J. Bullock, "Future and present trends of navigation and positioning techniques in exploration geophysics," Geophysical Journal, vol. 92, no. 3, pp. 521, 1988.

[3] A. A. R. Zohdy, G. P. Eaton, and D. R. Mabey, Application of surface geophysics to ground water investigations: Techniques of water-resources investigations of the United States Geological Survey, 1974, pp. 116

[4] J. S. Sumner, Principles of Induced Polarization for Geophysical Exploration, Developments in Economic Geology 5, Elsevier Science Publishing Co, 1976.

[5] J. M. Reynolds, An Introduction to Applied and Environmental Geophysics, New York: Wiley, 1997.

[6] Y. Rubin and S. S. Hubbard, "Hydrogeophysics, water science and technology library," Dordrecht, The Netherlands, Springer, vol. 50, pp. 523, 2006

[7] A. H. Said, "Geophysical imaging of root-zone, trunk, and moisture heterogeneity," Journal of Experimental Botany, vol. 58 (4) pp. 839-854, 2007.

[8] H. R. Burger, "Exploration geophysics of the shallow subsurface," Prentice Hall P T R., 1992.
[9] M. H. Loke, Instruction manual for the $2 D$ resistivity forward modeling program Res2Dmod, 1994, pp. 1-11.

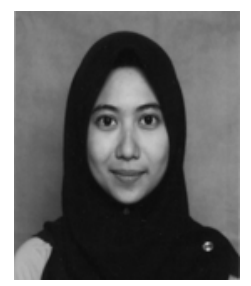

Muztaza M. Nordiana was born in Johor Bahru, Malaysia, on January 25, 1986. She was graduated BSc (2008) and MSc (2010) in Applied Science (Geophysics) at Universiti Sains Malaysia (USM), Malaysia. She is currently pursuing $\mathrm{PhD}$ at the same university. She is also conducting and teaching undergraduate and postgraduate students in their final year and research projects.

She has experienced working in field that involves engineering and environmental projects including slope, engineering and groundwater in all Peninsular Malaysia including Sarawak, Labuan and Brunei. Her research interest is about Geophysics in mineral exploration, engineering and environmental study.

Ms. Nordiana is a member of European Association of Geoscientists \& Engineers (EAGE) and Geological Society of Malaysia. She was obtained fellowship from USM. She was a recipient of the Student Travel Grant Saint Petersburg 2012 sponsor by EAGE Student Affairs. She has published several journals and refereed proceeding papers. She was also received best paper award from International Conference of Arts, Science \& Technology (ICAST 2012).

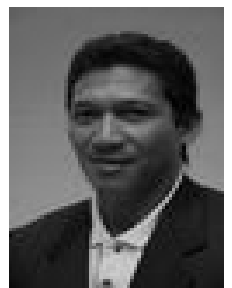

S. Rosli was born in Penang, Malaysia, on 28th February 1960. He is a senior lecturer in Geophysics section, School of Physics, Universiti Sains Malaysia (USM). He obtained his B.Sc from Universiti Sains Malaysia in 1984, M.Sc from USM in 2004 and was awarded a PhD in 2009 from USM. He has served at USM since year 1985.

Prior joining USM, he worked as Tutor in Matriculation Centre USM and School of Physics, USM. His current research activities are Engineering and Environment. He expertise is in Electrical method (2D/3D resistivity/ IP/ SP), Seismic (Refraction and Reflection), Ground Penetrating Radar, Magnetic and Gravity.

He has published several books and more than 80 journals and conference papers.

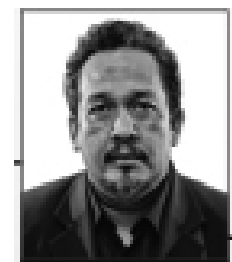

Saidin M. Mokhtar was born in Perak, Malaysia on $15^{\text {th }}$ August 1963 . He is currently the Director of the Centre for Global Archaeological Research (CGAR), Universiti Sains Malaysia (USM). He has involved in the field of archaeology since 1987, after obtaining his first degree in geology at Universiti Kebangsaan Malaysia. He acquired a PhD from USM in 1996 through a doctoral coursework at Harvard University. 
He is the Malaysian first archaeogeologist. With more than 20 years experience in archaeological research throughout the country, he has led Palaeolithic studies at sites Kampung Temelong, Lawin, Tingkayu, Bukit Bunuh, Mansuli, and civilization site of Sungai Batu, and was involved in the EIA Petronas Gas and Bakun Projects. His expertise is in the field of Palaeolithic culture, palaeoenvironment, early civilization and stone tools technology and classification.

Prof. Mokhtar is an Honarary Secretariat since 2007. He is also a member of Indo Pacific Prehistory Association (1990-2012), The Bosnain Valley of the Pyramids (2000-2012) and Geological Society of Malaysia (1987-2012). He was received Universiti Sains Malaysia Excellence Award (2001), $3^{\text {rd }}$ place in booth best award in MOSTE exhibition (2000) and $1^{\text {st }}$ place in booth best award (history section) in MOE exhibition (2001). He has published several books, journals and conference papers.

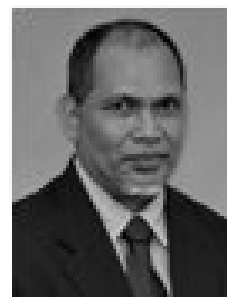

Nordin M. M. Nawawi was born in Negeri Sembilan, Malaysia, on $6^{\text {th }}$ July 1958 . He is a professor in Geophysics section, School of Physics, Universiti Sains Malaysia (USM). He was graduated BSc (1979) and M.Sc (1983) in Physics from Western Michigan University, USA. He obtained his Ph.D (1993) from Birmingham University, England in Geophysics.

He was a teaching assistant in Western Michigan University, USA (1981-1983). He works as a lecturer in Universiti Sains Malaysia (USM) since 1983. His research interests are Electrical Imaging and GPR for Geotechnical, Environment, Archaeology and Geophysics.

Prof. Dr. Nawawi is a member of European Association of Geoscientists and Engineers (EAGE), Environmental and Engineering Geophysical
Society (EEGS), Institute of Geology Malaysia and Geological Society of Malaysia. He was received Universiti Sains Malaysia Excellence Award (1998), Japanese Society for the Promotion of Science (JSPS) General Exchange Program Fellowship - Kyushu University (2000), Australian Endeavour Executive Award (Second Round) - Monash University, Australia (2010) and Ludger Mintrop Award 2012 presented to La Hamimu, Jamhir Safani and Mohd Nawawi for best paper published in Near Surface Geophysics for the year 2011. He has published several books, journals and conference papers.

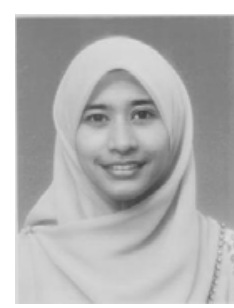

Ismail N. Azwin was born in Kedah, Malaysia, on $25^{\text {th }}$ September 1987 . She is currently a post-graduate student in Universiti Sains Malaysia (USM) pursuing her $\mathrm{PhD}$ in seismic and electromagnetic wave propagation characteristics. She graduated from USM in Master of Science (Geophysics) in September 2011 regarding the application of geophysical methods in engineering and environmental problems. She obtained her BSc from same university in August 2009.

She has field work experiences concerning geophysics-related in engineering and environmental projects including slope stability, groundwater exploration, constructions and also in archaeological research. Her research interest is about Geophysics in engineering and environmental study.

Ms. Nur Azwin is a member of European Association of Geoscientists \& Engineers (EAGE) and Geological Society of Malaysia. She has attended few conferences and published some refereed proceeding papers. 